American Journal of Applied Sciences 6 (7): 1277-1283, 2009

ISSN 1546-9239

(C) 2009 Science Publications

\title{
Product Quality and Effective Demand under Stagnation
}

\author{
Wataru Johdo \\ Department of Economics, Tezukayama University, \\ 7-1-1, Tezukayama, Nara 631-8501, Japan
}

\begin{abstract}
Problem statement: Recent neoclassical theoretical study, particularly in the endogenous growth literature, has studied the nature of the relationship between economic growth and product quality. However, little attention has been given to the impact of a rise in product quality on effective demand under stagnation. This is because previous models have assumed that demand is always met with supply in labor and products markets. Therefore, the question remains as to whether a rise in product quality increases effective demand when stagnation occurs. Approach: This study applied an idea of stagnation and combined it with a quality ladder model to account for the relationship between product quality and effective demand under stagnation. Using this extended framework, this study examined the impact on effective demand of an $\mathrm{R}$ and $\mathrm{D}$ subsidy that improved product quality when stagnation occurs. Results: The results indicated that a rise in product quality increased the efficiency of consumption utility function and thereby enabled people to enjoy higher utility while consuming the same amount. However, under stagnation, people chose not to increase their utility, causing realized consumption to decrease and saving to increase. Consequently, effective demand decreased and the stagnation worsened. Conclusion: From the results, it can be concluded that use of R and D subsidies that improves product quality is not appropriate for a country where stagnation occurs.
\end{abstract}

Key words: Stagnation, quality ladder, effective demand, R and D subsidy

\section{INTRODUCTION}

The Japanese economy has been facing persistent stagnation since the stock market bubble collapsed in 1990. Recently, the Japanese government has used various policies, such as deregulation, privatization and subsidies for Research and Development ( $R$ and $D$ ), to stimulate the economy. These policies, called "Kouzoukaikaku" in Japanese, are intended to foster a recovery in the Japanese economy by stimulating production by encouraging new commodities and services. The recent history of business in Japan shows that high growth rates were attained in the late 1990s because of the Information Technology (IT) revolution (the so-called "IT boom"). However, in 2001, the performance of IT-allied industries deteriorated and the rate of economic growth fell, raising unemployment. Despite the remarkable development of innovative products by IT industries and despite rapid acceptance of these products by consumers, why did the growth rate fall and unemployment rise in 2001. In fact, Japan's GDP growth rate was 3.0\% for 2000 but it fell to- $1.2 \%$ for 2001, whereas Japan's unemployment rate was $4.7 \%$ for both 1999 and 2000 but it rose to $5.0 \%$ for $2001^{[4]}$. Motivated by this observation, we investigate whether IT investment-enhancing policy improves or worsens aggregate economic activity under stagnation, using a dynamic optimization model.

Recent neoclassical theoretical work, particularly in the endogenous growth literature, has studied the nature of the relationship between economic growth and product quality ${ }^{[1-3,11-13]}$. However, they ignore the impact of product quality on effective demand under stagnation because previous models have assumed that demand is always met with supply in labor and products markets. Thus, the question remains as to whether a rise in product quality increases effective demand when stagnation occurs.

In contrast to the literature described above, the possible existence of a stagnation equilibrium is investigated in $\mathrm{Ono}^{[8]}$. The study of $\mathrm{Ono}^{[8]}$ gives a reinterpretation of Chapter 17 of Keynes's General Theory, which is concerned with shortage of effective demand. Ono ${ }^{[8]}$ shows that stagnation may occur when two assumptions, which differ from neoclassical assumptions, are fulfilled. These are insatiable liquidity preference, $\quad \lim \mathrm{v}^{\prime}(\mathrm{m})=\beta$ for $\mathrm{m} \rightarrow \infty$ (i.e., $\mathrm{Ono}^{[8]}$ introduces money to the utility function) and sluggish price adjustments. It is found that "Keynes's rule"-an equilibrium condition-may not be fulfilled unless consumption, c, is less than output, y, i.e., effective demand shortage. This main result is seen from 
"Keynes's rule" in the steady state, that $\rho+\pi_{p}=R=v^{\prime}(m) / u^{\prime}(c)$, where $\rho+\pi_{p}$ is the nominal rate of time preference, $\pi_{p}$ is the instant rate of inflation, $\mathrm{R}$ is the return to equities and $\mathrm{v}^{\prime}(\mathrm{m}) / \mathrm{u}^{\prime}(\mathrm{c})$ is the liquidity premium. From $\lim \mathrm{v}^{\prime}(\mathrm{m})=\beta$ for $\mathrm{m} \rightarrow \infty$, the lower bound of the liquidity premium equals $\beta / \mathrm{u}^{\prime}(\mathrm{c})$. Therefore, it may be the case that $\rho<R=\beta / u^{\prime}(y)$ requires that $\mathrm{c}<\mathrm{y}$, implying that, under a sluggish price adjustment, effective demand shortage with deflation (i.e., stagnation) occurs. Furthermore, using such a model, Ono ${ }^{[8]}$ considers the effective demand effects of various demand stimulus policies, such as additional fiscal spending and monetary expansion. However, Ono $^{[8]}$ ignores the impacts of a rise in product quality on effective demand.

This study applies the idea of stagnation in Ono ${ }^{[8]}$ and combines it with the quality ladder model of Grossman and Helpman ${ }^{[1]}$ to account for the relationship between product quality and effective demand under stagnation. This combination implies that the production side of the model is more complicated than the model of Ono $^{[8]}$. In Ono ${ }^{[8]}$ there is one commodity with output $y$ that is produced costlessly by firms (like a mineral spring or a tree). Adopting the production side of Grossman and Helpman $^{[1]}$ implies infinitively many commodities produced with labor as the production factor. Furthermore, firms possess market power. Using this extended framework, the study examines the effect of an $\mathrm{R}$ and $\mathrm{D}$ subsidy on the steady state levels of effective demand.

\section{MATERIALS AND METHODS}

This study builds on Johdo ${ }^{[5]}$. We integrate Grossman and Helpman ${ }^{[1]}$ and the idea of stagnation in Ono ${ }^{[8]}$ to consider a monetary economy with innovation. The model here also shares similarities with other quality ladder models such as those in Grossman and Helpman $^{[2,3]}$ and Segerstrom ${ }^{[11,12]}$. The representative household has preferences over a continuum of products indexed by $\mathrm{j}$ and for real money balances. The set of products consists of the interval $[0,1]$ whose measure is one. Each product $\mathrm{j}$ can be improved by innovation. These improvements require profitmotivated $\mathrm{R}$ and $\mathrm{D}$ investment. The state-of-the-art product in each industry is produced using linear technology with labor. The government promotes innovation through an $\mathrm{R}$ and $\mathrm{D}$ subsidy and imposes a lump-sum tax on households or issues riskless government bonds in order to finance the subsidy.

Household: The real-flow budget constraint of the representative household is: $\dot{\mathrm{a}}=\mathrm{ra}+\mathrm{w} \ell^{\mathrm{s}}-\mathrm{Rm}-\mathrm{c}-\mathrm{z}$

Where:

$\mathrm{a}=$ The real value of total asset holdings consisting of riskless government bonds $b_{g}{ }^{d}$ equities $b_{p}{ }^{d}$ and real money balances $m$

$\mathrm{a}=\mathrm{b}_{\mathrm{g}}{ }^{\mathrm{d}}+\mathrm{b}_{\mathrm{p}}{ }^{\mathrm{d}}+\mathrm{m}$

$\mathrm{r}=$ The real market rate of return:

$\mathrm{W}(\equiv \mathrm{W} / \mathrm{P})($ the real wage rate)

Where:

$\mathrm{W}=$ The nominal wage rate

$\mathrm{P}=$ Price level and

$\ell^{\mathrm{s}}=$ Labor supply, determined according to $\ell^{\mathrm{s}}=\min [\mathrm{s}$, $\mathrm{x}+\phi 1$ ] which implies that realized labor supply is determined on the short side either as inelastic labor supply s or as the actual labor demanded by manufacturing $(=\mathrm{x})$ and $\mathrm{R}$ and $\mathrm{D}$ activities $(=\phi \mathrm{l})$

In addition, $\mathrm{c}$ denotes a consumption index defined below, $z$ is the lump-sum tax and $R\left(=r+\pi_{p}\right)$ is the nominal market rate of return where $\pi_{\mathrm{p}}$ the instant inflation rate. Lower case letters denote real variables and capital letters denote nominal variables. Thus, the nominal budget equation is represented by:

$$
\dot{\mathrm{A}}=\mathrm{RB}+\mathrm{W} \ell^{\mathrm{s}}-\mathrm{Pc}-\mathrm{Pz}
$$

where, $\mathrm{B}$ denotes the sum of equities $\left(\equiv \mathrm{B}_{\mathrm{p}}\right)$ and riskless government bonds $\left(\equiv \mathrm{B}_{\mathrm{G}}\right)$. The lifetime utility of the household is given by:

$\mathrm{U}=\int_{0}^{\infty}[\log \mathrm{c}+\mathrm{v}(\mathrm{m})] \mathrm{e}^{-\rho \mathrm{t}} \mathrm{dt}$

$v^{\prime}(m)>0, v^{\prime \prime}(m) \leq 0, v^{\prime}(\infty)=\beta>0$

Where:

$\log \mathrm{c}=$ Instantaneous utility defined below

$\mathrm{v}(\mathrm{m})=$ Liquidity preference

$\rho \quad=$ The subjective discount rate

In addition, $v^{\prime}(\infty)=\beta>0$ implies that there is no saturation point in the individual's liquidity preference even if real money balances m keep increasing. Ono et $a l^{[10]}$ attempt to provide a justification for the existence of insatiable liquidity preference by testing for it empirically in Japan using two data sets, prefectural and individual. In their empirical investigation, Ono et al. ${ }^{[10]}$ use two different econometric methods-parametric and nonparametric. 
Ono et al. ${ }^{[10]}$ show that insatiable liquidity preference is significantly positive at standard significance levels.

Before turning to the dynamic problem, we consider the composition of a given level of $\mathrm{E}$ at each instant to maximize $\log \mathrm{c}$. Instantaneous utility is given by:

$\log c(t)=\int_{0}^{1} \log \left[\Sigma_{n} q_{n}(j) x_{n t}(j)\right] d j$

Where:

$\mathrm{q}_{\mathrm{n}}(\mathrm{j})=$ The quality of the nth generation of product in industry $\mathrm{j}$

$x_{n t}(j)=$ Consumption of quality $n$ of product $j$ at time $t$

Here, we assume $q_{n}(j)=\lambda q_{n-1}(j)$ and we take $\lambda>1$ to be an exogenous parameter and identical to all industries. In addition, we assume that the lowest quality of each product offers one unit of service and therefore, $q_{n}(j)=\lambda^{n}$, which represents the highest quality after $n$ improvements of product $j$.

We now take a particular point in time and define nominal spending $\mathrm{E}$ at that point of time as:

$$
E(t)=\int_{0}^{1} \sum_{n=0}^{\infty} P_{n t}(j) x_{n t}(j) d j
$$

where, $P_{n t}(j)$ is the price of quality $n$ of product $j$ at time t. Subject to this, the individual determines $x_{n t}(j)$ to maximize (3).

The household then spends its nominal income $\mathrm{E}$ (t) evenly across all product lines and purchases a single variety in each line that offers the lowest qualityadjusted price. This yields the following demand functions:

$x_{n t}=\left\{\begin{array}{cc}\frac{E(t)}{P_{n t}(j)} & \text { for } n=\tilde{n}_{t}(j) \\ 0 & \text { otherwise }\end{array}\right.$

and the price index corresponding to (3) is:

$P=\exp \left\{\int_{0}^{1} \log \left[\frac{\tilde{P}(j)}{\tilde{q}(j)}\right] d j\right\}$

where, $\tilde{\mathrm{P}}(\mathrm{j})$ and $\tilde{\mathrm{q}}(\mathrm{j})$ are the price and quality, respectively, of the state-of-the-art product. We shall refer to (5) as the price level. Then, from (3, 4 and 5), we obtain $\mathrm{c}=\mathrm{e}(\equiv \mathrm{E} / \mathrm{P})$, where e represents real consumption expenditure.
We return to the dynamic problem. The Hamiltonian is given by:

$$
H=[\log e+v(m)] e^{-\rho t}+\mu\left[r a+w \ell^{s}-R m-e-z\right]
$$

The first-order conditions for this problem are $(1 / \mathrm{e}) \mathrm{e}^{-\rho t}=\mu$ and $-\dot{\mu}=\mathrm{r} \mu, \mathrm{v}^{\prime}(\mathrm{m}) \mathrm{e}^{-\rho \mathrm{t}}=\mathrm{R} \mu$ and the transversality condition is $\lim _{t \rightarrow \infty} \mu_{t} a_{t}=0$. From the first order conditions, we obtain:

$\rho+\dot{\mathrm{e}} / \mathrm{e}+\pi_{\mathrm{p}}=\mathrm{R}=\mathrm{v}^{\prime}(\mathrm{m}) \mathrm{e}$

Ono $^{[8]}$ calls this "Keynes's rule". The Left Hand Side (LHS) of (6) shows the time preference rate and the Right Hand Side (RHS) represents the liquidity premium of money, which is the marginal rate of substitution between consumption and money holdings.

Production and $\mathbf{R}$ and $\mathbf{D}$ races: For each industry and each product quality, one unit of labor is needed to produce one unit of output; that is $y(j)=\ell(j)$, where, $y(j)$ is the firm's output, $\ell(j)$ is labor input. This makes the marginal cost of every product equal to the nominal wage rate $\mathrm{W}$. In addition, we assume that all producers (or leaders) offering the state-of-the-art product in each industry $\mathrm{j}$ compete as price-setting oligopolists.

Following Grossman and Helpman ${ }^{[1]}$, the outcome of oligopolistic competition in industry $\mathrm{j}$ is as follows. The leader offering the state-of-the-art product practices limit pricing in the Bertrand-Nash equilibrium, thereby driving the nearest competitor from the market:

$P(j)=\lambda W$

This quality-adjusted price, $\lambda \mathrm{W}$, ensures the leader maximum profits for industry $\mathrm{j}$. In addition, as $\mathrm{W}$ is given, (7) yields $P(j)=\bar{P}, \forall j$. These relationships imply that each industry leader supplies the same quantity. From (4) and (7), the nominal profit flow $\left(\equiv \Pi_{R}\right)$ is:

$\Pi_{\mathrm{R}}=[1-(1 / \lambda)] \mathrm{E}$

Dividing (8) by $\mathrm{P}$ yields the real profit $\left(\equiv \pi_{\mathrm{R}}\right)$

$\pi_{\mathrm{R}}=[1-(1 / \lambda)] \mathrm{e}$

The stream of real profits for the leader continues until someone else (or an entrepreneur) succeeds in improving upon the leader's product.

Next, we turn to $R$ and $D$ races. We assume that forward-looking entrepreneurs decide on the amount of $\mathrm{R}$ and $\mathrm{D}$ investment and that the assumed $\mathrm{R}$ and $\mathrm{D}$ technology is linear, in which the instantaneous 
probability of success in innovation is directly proportional to labor devoted to this activity. In addition, we assume entrepreneurs issue equities to finance the cost of $\mathrm{R}$ and $\mathrm{D}$ and all profits are distributed to shareholders as dividends when $\mathrm{R}$ and $\mathrm{D}$ activities result in success. To consider the incentive for entrepreneurs to engage in innovative $R$ and $D$, let $k$ denote the expected discounted profit for winning an innovative $\mathrm{R}$ and $\mathrm{D}$ race. An entrepreneur that undertakes $\mathrm{R}$ and $\mathrm{D}$ activities at intensity $\mathrm{l}$ for an interval of time of length dt succeeds in developing the next generation of the targeted product with probability ıdt. This effort requires $\phi$ units of labor for the same interval. Under the symmetric equilibrium, any entrepreneur undertakes $\mathrm{R}$ and $\mathrm{D}$ activities with equal intensity, regardless of the product $\mathrm{j}$ or its current quality level. Free entry into the innovative $R$ and $D$ race, therefore, implies:

$(1-\tau) \phi w \geq k$ with equality whenever $\mathrm{l}>0$

where, $\tau$ is $R$ and $D$ subsidy spending. The free entry condition (10) is compatible with corner solutions in which innovation halts i.e. $l=0$ when $(1-\tau) \phi \mathrm{w}=\mathrm{k}$.

Government and No-arbitrage condition: We suppose that the government provides a subsidy to $\mathrm{R}$ and $\mathrm{D}$ activities, which it finances out of a lump-sum tax or by issuing riskless government bonds. Therefore, the government operates in accordance with its flow budget constraint, $\dot{\mathrm{b}}_{\mathrm{g}}{ }^{\mathrm{s}}=\mathrm{rb}_{\mathrm{g}}{ }^{\mathrm{s}}+\tau \mathrm{w} \phi \mathrm{l}-\mathrm{z}$ where $\mathrm{b}_{\mathrm{g}}{ }^{\mathrm{s}}$ represents real supply of riskless government bonds. We also assume that whenever the government changes the subsidy, it adjusts the time path of debt and/or lump-sum tax to satisfy its budget constraint.

Next, we consider the stock-market valuation of profit-making firms. A no-arbitrage condition relates expected equity returns to the return on a riskless bond. As $\mathrm{R}$ and $\mathrm{D}$ outcomes in different industries are uncorrelated, the risks facing any industry leader are idiosyncratic. Shareholders can therefore earn a no-risk return by owning a diversified portfolio. Thus, the expected return on any equity must equal the return on an equal size investment in a riskless bond:

$\pi_{\mathrm{R}} / \mathrm{k}+\mathrm{k} / \mathrm{k}-\mathrm{l}=\mathrm{r}$

In (11), the third term of the left hand side is the rate of capital loss in case that an entrepreneur succeeds in developing the next generation of incumbent reader's product.
Market Equilibrium and Dynamic System: The money market, equity market and bond market are assumed always to clear:

$\mathrm{m}=\mathrm{M}^{\mathrm{s}} / \mathrm{P}, \mathrm{b}_{\mathrm{p}}{ }^{\mathrm{d}}=\mathrm{k}, \mathrm{b}_{\mathrm{g}}{ }^{\mathrm{d}}=\mathrm{b}_{\mathrm{g}}{ }^{\mathrm{s}}$

where, $\mathrm{M}^{\mathrm{s}}$ represents total nominal money supply. In the labor market, labor is demanded by manufacturing and $\mathrm{R}$ and $\mathrm{D}$ activities. Innovators require $\phi \mathrm{l}$ units of labor, while manufacturing requires $\mathrm{x}(=\mathrm{y}=\ell)$ units of labor. Hence, from the unity of industry measure, total labor demand is $\mathrm{x}+\phi \mathbf{l}$. As nominal wages take time to adjust excess labor demand in the real world, as in $\mathrm{Ono}^{[8]}$, we also assume that nominal wage-rate adjustment is sluggish and formulate it as the following process:

$$
\dot{\mathrm{W}} / \mathrm{W}=\alpha\{(\mathrm{x}(\mathrm{e}, \mathrm{k})+\phi \mathrm{l}) / \mathrm{s}]-1\}=\alpha\{[((1-\tau) \phi \mathrm{e} / \lambda \mathrm{k}+\phi \mathrm{l}) / \mathrm{s}]-1\}
$$

where, $\alpha$ is the constant exogenous parameter that represents the speed of nominal-wage adjustment and $\mathrm{x}=\mathrm{x}(\mathrm{e}, \mathrm{k})$ is derived by using (4), (7) and (10). Johdo ${ }^{[6]}$, Matsuzaki $^{[7]}$ and $\mathrm{Ono}^{[9]}$ also use this type of sluggish adjustment mechanism. From (13), W adjusts according to the ratio of excess labor demand $[(x(e, k)+\phi l)-s]$ to labor supply s. Naturally, when full employment holds, i.e., $\mathrm{x}+\phi \mathrm{l}=\mathrm{s}$, (13) yields $\dot{\mathrm{W}} / \mathrm{W}=0, \forall \alpha$. From (9) and (11), we obtain:

$\dot{\mathrm{q}} / \mathrm{q}=\mathrm{r}+\mathrm{l}-[(1-(1 / \lambda)) \mathrm{e}] / \mathrm{k}$

Substituting (4) and (7) into (3) yields:

$\log D(t)=\int_{0}^{1} \log \tilde{q}_{t}(j) d j+\log x(e, k)$

The first term of (15) is rewritten as:

$\int_{0}^{1} \log \tilde{\mathrm{q}}_{\mathrm{t}}(\mathrm{j}) \mathrm{dj}=\sum_{\mathrm{n}=0}^{\infty} \mathrm{f}(\mathrm{m}, \mathrm{t}) \log \lambda^{\mathrm{n}}=\mathrm{tt} \log \lambda$

where $f(m, t)$ shows the probability that a given product will take $\mathrm{m}$ improvements in quality over a time length $t$. The third term of (16) is derived from the properties of the Poisson distribution and it denotes the expected number of improvements ${ }^{[1]}$. From $(5,7$ and 16), we have $\log \mathrm{P}=\log \mathrm{W}+\log \lambda-\mathrm{tt} \log \lambda$ and differentiating this with respect to time yields:

$\dot{\mathrm{P}} / \mathrm{P}\left(\equiv \pi_{\mathrm{P}}\right)=\dot{\mathrm{W}} / \mathrm{W}-\operatorname{llog} \lambda$ 
Am. J. Applied Sci., 6 (7): 1277-1283, 2009 is:

From (13) and (17), the dynamic of real balances

$\dot{\mathrm{m}} / \mathrm{m}=-\pi_{\mathrm{P}}=-\alpha([((1-\tau) \phi \mathrm{e} / \lambda \mathrm{k}+\phi \mathrm{l}) / \mathrm{s}]-1)+\mathrm{llog} \lambda$

From (6, 13 and 17), "Keynes's rule" is rewritten as:

$\rho+\dot{\mathrm{e}} / \mathrm{e}+\alpha([((1-\tau) \phi \mathrm{e} / \lambda \mathrm{k}+\phi \mathrm{l}) / \mathrm{s}]-1)-\mathrm{l} \log \lambda=\mathrm{R}=\mathrm{v}^{\prime}(\mathrm{m}) \mathrm{e}$

Thus (10, 12, 13, 14, 18 and 19) and $R=r+\pi_{P}$ constitute an autonomous dynamic system for $\mathrm{e}, \mathrm{l}, \mathrm{m}, \mathrm{k}$, $r, R, W$ and $\mathrm{P}$. We turn in the next section to the characterization of the steady state with stagnation.

Steady state with stagnation: In this study, we define the steady state with stagnation as the state in which effective demand shortage and involuntary unemployment coexist and innovation halts, thereby bringing persistent deflation. The steady state with stagnation, therefore, is represented a pair $\left(\mathrm{e}^{*}, \mathrm{k}^{*}\right)$ in which $\dot{\mathrm{r}}=0, \dot{\mathrm{R}}=0, \dot{\mathrm{q}}=0, \dot{\mathrm{k}}=0, \mathrm{r}=0, \dot{\mathrm{e}}=0, \pi_{\mathrm{p}}<0$ and $\dot{\mathrm{m}}>0$ hold. The above definition means that not only the real and nominal rates of interest are fixed, but also q, $\mathrm{k}$ and e remain constant. In addition, from (15), (16) and $\mathrm{l}=0$, we have $\log \mathrm{D}(\mathrm{t})=\log \mathrm{x}\left(\mathrm{e}^{*}, \mathrm{k}^{*}\right)$. As $\mathrm{e}^{*}$ and $\mathrm{k}^{*}$ are constant, $\mathrm{x}\left(\mathrm{e}^{*}, \mathrm{k}^{*}\right)$ and $\mathrm{D}\left(=\mathrm{e}^{*}\right)$ are also constant in the steady state. Furthermore, the steady state with stagnation requires the existence of involuntary unemployment, causing nominal wages, nominal prices and the price level to continue to decline and therefore $\mathrm{m}$ diverges infinitely. This is because, from (7), (17) and $\mathrm{\imath}=0, \dot{\mathrm{P}} / \mathrm{P}\left(\equiv \pi_{\mathrm{P}}\right)=\dot{\mathrm{P}}(\mathrm{j}) / \mathrm{P}(\mathrm{j})=\dot{\mathrm{W}} / \mathrm{W}$ holds in the steady state.

Now, we find the condition required for unemployment and consumption to coexist under stagnation in the steady state. Here, we assume for simplicity that $v^{\prime}(m)=\beta>0$ at the initial time, so that the transition process does not exist in this model since real balances disappears from "Keynes's rule", (19). The economy therefore jumps immediately to the steady state at the initial time. Then, (19) is rewritten as:

$\rho+\alpha\left(\left[\left((1-\tau) \phi \mathrm{e}^{*} / \lambda \mathrm{k}^{*}\right) / \mathrm{s}\right]-1\right)=\mathrm{R}=\beta \mathrm{e}^{*}$

Furthermore, since $e$ remain constant, $\mathrm{r}=\rho$ is valid from (6). Hence, from (9) and (11), we obtain:

$\mathrm{k}^{*}=(1-(1 / \lambda))\left(\mathrm{e}^{*} / \rho\right)$

Substituting this into (20) yields: $\rho+\alpha\left(\left[(1-\tau)(\lambda-1)^{-1} \phi \rho / s\right]-1\right)=\mathrm{R}=\beta \mathrm{e}^{*}$

Then, from (21), we obtain the following the steady-state consumption value:

$\mathrm{e}^{*}=\left\{\rho+\alpha\left(\left[(1-\tau)(\lambda-1)^{-1} \phi \rho / s\right]-1\right)\right\} / \beta$

First, we find the condition required for steadystate consumption under stagnation. Steady state consumption under stagnation must not only exceed zero, but also must be below the full-employment production level. Thus, steady-state consumption must satisfy $0<\mathrm{e}^{*}<\mathrm{e}_{\mathrm{f}}$, where $\mathrm{e}_{\mathrm{f}}$ is the full-employment production level that is compatible with the labor market clearing condition:

$$
\mathrm{x}\left(\mathrm{e}^{*}, \mathrm{k}^{*}\left(\mathrm{e}^{*}\right)\right) / \mathrm{s}=1\left(\Leftrightarrow \mathrm{x}\left(\mathrm{e}^{*}, \mathrm{k}^{*}\left(\mathrm{e}^{*}\right)\right)=\mathrm{s}\right)
$$

where, $\mathrm{x}\left(\mathrm{e}^{*}, \mathrm{k}^{*}\left(\mathrm{e}^{*}\right)\right)$ is the total labor demand and $\mathrm{s}$ is the total labor supply. Substituting $\mathrm{x}\left(\mathrm{e}^{*}, \mathrm{k}^{*}\left(\mathrm{e}^{*}\right)\right) / \mathrm{s}=1$ into (21) yields the full-employment production level as $e_{f}=\rho / \beta$. From $e_{f}=\rho / \beta$ and $(22)$, for $0<e^{*}<e_{f}$, the following condition must hold (Fig. 1):

$1>(1-\tau)(\lambda-1)^{-1} \phi \rho / s$ and $\rho>\alpha$

Next, we find the condition required for unemployment to exist in the steady state, i.e., $\mathrm{x}\left(\mathrm{e}^{*}, \mathrm{k}^{*}\left(\mathrm{e}^{*}\right)\right) / \mathrm{s}<1\left(\Leftrightarrow \mathrm{x}\left(\mathrm{e}^{*}, \mathrm{k}^{*}\left(\mathrm{e}^{*}\right)\right)<\mathrm{s}\right)$. From (21), the ratio of labor demand to supply in the steady state can be rewritten as $\mathrm{x}\left(\mathrm{e}^{*}, \mathrm{k}^{*}\left(\mathrm{e}^{*}\right)\right) / \mathrm{s}=(1-\tau)$ $(\lambda-1)^{-1} \phi \rho / \mathrm{s}$. Therefore, for $\mathrm{x}\left(\mathrm{e}^{*}, \mathrm{k}^{*}\left(\mathrm{e}^{*}\right)\right) / \mathrm{s}<1$, the following condition must hold:

$1>(1-\tau)(\lambda-1)^{-1} \phi \rho / \mathrm{s}$

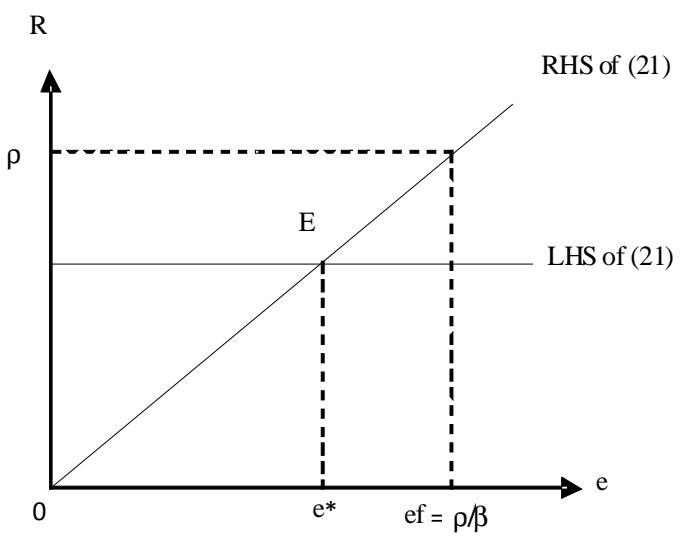

Fig. 1: Steady state with stagnation 
From (23) and (24), if a steady-state consumption is $\mathrm{e}^{*}<\mathrm{e}_{\mathrm{f}}$, then we obtain $\mathrm{x}\left(\mathrm{e}^{*}, \mathrm{k}^{*}\left(\mathrm{e}^{*}\right)\right) / \mathrm{s}<1$ and thus unemployment also occurs in the steady state. For reasons mentioned above, if we set the conditions, $1>(1-\tau)(\lambda-1)^{-1} \phi \rho / s$ and $\rho>\alpha$, then an economy can fall into stagnation in which unemployment and an effective demand shortage coexist. To sum up, the parameters of this model must satisfy (23) for $\mathrm{x}\left(\mathrm{e}^{*}, \mathrm{k}^{*}\left(\mathrm{e}^{*}\right)\right) / \mathrm{s}<1$ and $0<\mathrm{e}^{*}<\mathrm{e}_{\mathrm{f}}$ to hold together in the steady state.

The conditions (23) show that if $\phi$ and $\alpha$ are low enough, $\lambda$ and $s$ are large enough, then an economy falls into stagnation. Intuitively, these parameter conditions show a high quality increment (from large $\lambda$ ) and a low R\&D labor cost (from low $\phi$ and large $s$ ) so that higher quality and frequent innovations are possible. It not only enables the household to enjoy enough consumption but also lowers the time preference rate of Keynes's rule (21). The latter implies that the desire for consumption decreases, while the desire to hold money increases. Thus, insufficient consumption is attained, causing an effective demand shortage and consequently an economy falls into stagnation. Furthermore, from (18) and (19), the steady state validates the transversality condition $\dot{\mathrm{m}} / \mathrm{m}=-\pi_{\mathrm{P}}=\rho-\beta \mathrm{e}^{*}<\rho$. In what follows, we assume that (23) is valid so that a steady state with stagnation exists in this economy.

\section{RESULTS}

We now consider the effects on effective demand of an unanticipated increase in an $\mathrm{R}$ and $\mathrm{D}$ subsidy that leads to an increase of product quality, under stagnation. From (21), the impact on effective demand of a rise in the subsidy is:

$$
\mathrm{de}^{*} / \mathrm{d} \tau=-\alpha \phi \rho(\lambda-1)^{-1} / \beta \mathrm{s}<0
$$

Thus, we obtain the following proposition:

Proposition 1: In the steady state with stagnation, an increase of an R and D subsidy that leads to an increase of product quality decreases effective demand.

The above proposition is explained intuitively as follows. The rise in the $\mathrm{R}$ and $\mathrm{D}$ subsidy initially raises product quality and thereby increases the efficiency of the consumption utility function. It enables people to enjoy higher utility by consuming the same amount. However, it lowers the time preference rate of Keynes's rule, while not affecting the liquidity premium that represents the desire to hold money. Hence, under stagnation, people feel they are consuming excessively,

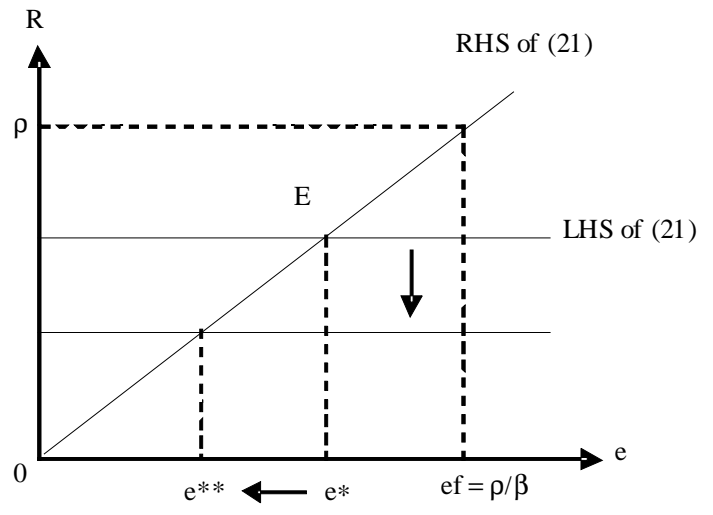

Fig. 2: The effect of R and D subsidy

causing realized consumption to decrease and saving to increase. Consequently, effective demand decreases. Figure 2 shows the effect of the subsidy on effective demand using Keynes's rule (21). Here, if we consider the consumption index represented by (3) along with a final goods production function where the input is intermediate goods, the index level can be taken as the productivity of production technology. In this case, we can give the proposition another intuition. That is, first, for given steady state consumption, innovation stimulated by the rise in the $\mathrm{R}$ and $\mathrm{D}$ subsidy increases the efficiency of the production function of final goods. It enables final goods producers more output using the same intermediate input. However, under stagnation, effective demand shortages persist. Hence, when final goods producers produce more efficiently due to the subsidy, demand for the intermediate input will decrease and employment required by the intermediate sector will also decrease. This decrease in employment leads to a decrease in the rate of time preference through a decline in the inflation rate (LHS of (21) falls) and consequently consumption (or effective demand) falls $\left(\mathrm{e}^{*} \rightarrow \mathrm{e}^{* *}\right)$.

\section{DISCUSSION}

Neoclassical macroeconomics has devoted enormous energy to the question of whether $\mathrm{R}$ and $\mathrm{D}$ subsidy increases economic growth. However, most models in the endogenous growth literatures are based on the assumption of full employment. By contrast, this study has provided a characterization of the role of $\mathrm{R}$ and $\mathrm{D}$ subsidy in the determination of effective demand under stagnation.

\section{CONCLUSION}

The main result is as follows. A rise in the $R$ and D subsidy that leads to an increase of product quality 
enables people to enjoy higher utility by consuming the same amount. However, it lowers the time preference rate, while not affecting the liquidity premium that represents the desire to hold money. Hence, under stagnation, people feel they are consuming excessively, causing realized consumption to decrease and the stagnation worsens furthermore. Thus, we obtain a policy implication from this model that the use of subsidies is not appropriate for a country where stagnation occurs. In addition, this study generated realistic predictions about the effect of the IT revolution on Japan's business recession.

\section{ACKNOWLEDGEMENT}

The researcher is grateful to have received financial support from Tezukayama University.

\section{REFERENCES}

1. Grossman, G.M. and E. Helpman, 1991. Innovation and Growth in the Global Economy. MIT Press, Cambridge, ISBN: 0262071363, pp: 84.

2. Grossman, G.M. and E. Helpman, 1991. Quality ladders and product cycles. Q. J. Econ., 106: 557-586. http://ideas.repec.org/a/tpr/qjecon/v106y1991i2p55 7-86.html

3. Grossman, G.M. and E. Helpman, 1991. Quality ladders in the theory of growth. Rev. Econ. Stud., 58: 43-61.

http://ideas.repec.org/a/bla/restud/v58y1991i1p4361.html

4. IMF., 2003. International Financial Statistics LVI., 7. http://www.imf.org/external/pubs/cat/longres.cfm? sk $=16698.0$

5. Johdo, W., 2000. An improvement in product quality and the effective demand effect (In Japanese). Osaka Econ. Paper, 50: 35-45. http://ci.nii.ac.jp/naid/110004850355/
6. Johdo, W., 2000. Public policies for promoting competition and effective demand (In Japanese). JCER. Econ. J., 40: 129-141. http://www.jcer.or.jp/academic_journal/jer/detail23 3.html\#7

7. Matsuzaki, D., 2003. The effects of a consumption tax on effective demand under stagnation. Jap. Econ. $\quad$ Rev., 54: 101-118. http://papers.ssrn.com/sol3/papers.cfm?abstract_id $=411123$

8. Ono, Y., 2001. A reinterpretation of chapter 17 of keynes's general theory: Effective demand shortage under dynamic optimization. Int. Econ. Rev., 42: 207-236.

http://papers.ssrn.com/sol3/papers.cfm?abstract_id $=899044$

9. Ono, Y., 2006. International asymmetry in business activity and appreciation of a stagnant country's currency. Jap. Econ. Rev., 57: 101-120. http://papers.ssrn.com/sol3/papers.cfm?abstract_id $=886605$

10. Ono, Y., K. Ogawa and A. Yoshida, 2004. Liquidity trap and persistent unemployment with dynamic optimizing agents: Empirical evidence. Jap. Econ. Rev., 55: 355-371. http://papers.ssrn.com/sol3/papers.cfm?abstract_id=6 25424

11. Segerstrom, P.S., 1991. Innovation, imitation and economic growth. J. Political Econ., 99: 807-827. http://econpapers.repec.org/paper/fthmistet/8818.htm

12. Segerstrom, P.S., 1998. Endogenous growth without scale effects. Am. Econ. Rev., 88: 1290-1310. http://ideas.repec.org/a/aea/aecrev/v88y1998i5p12 90-1310.html

13. Segerstrom, P.S., 2000. The long-run growth effects of R and D subsidies. J. Econ. Growth, 5: 277-305.

http://econpapers.repec.org/paper/hhsiuiwop/0506. htm 